\title{
Unilateral cryptorchidism induces morphological changes of testes and hyperplasia of Sertoli cells in a dog
}

\author{
Joon Ho Moon ${ }^{1,4 \#}$, Dae Young Yoo ${ }^{2,4 \#}$, Young Kwang Jo ${ }^{1,4}$, Geon A Kim ${ }^{1,4}$, Hyo Young Jung, \\ Jung Hoon $\mathrm{Choi}^{3}$, In Koo Hwang ${ }^{2,4 *}$, Goo Jang ${ }^{1,4,5,6 *}$ \\ ${ }^{1}$ Laboratory of Theriogenology and Biotechnology, Department of Veterinary Clinical Sciences, \\ College of Veterinary Medicine, Seoul National University, Seoul, Korea \\ ${ }^{2}$ Department of Anatomy and Cell Biology, College of Veterinary Medicine, Seoul National University, Seoul, Korea \\ ${ }^{3}$ Department of Anatomy, College of Veterinary Medicine, Kangwon National University, Chuncheon, Korea \\ ${ }^{4}$ BK21 PLUS Program for Creative Veterinary Science Research, and Research Institute for Veterinary Science, \\ Seoul National University, Seoul, Korea \\ ${ }^{5}$ Institute of Green Bio Science \& Technology, Seoul National University, Pyeong Chang, Kangwon-do, Korea \\ ${ }^{6}$ Emergence Center for Food-Medicine Personalized Therapy System, Advanced Institutes of Convergence Technology, \\ Seoul National University, Gyeonggi-do, Korea
}

\begin{abstract}
Cryptorchidism is one of the most common genital defects in dogs. This study investigated the effects of abdominal cryptorchidism on morphology, cell proliferation, and Sertoli cell condition in a dog with spontaneous unilateral cryptorchidism. Elective orchidectomy was performed on the abdominal right testis and the scrotal left testis. Significant reductions in numbers of spermatogonia, spermatocytes, and spermatids were observed in hematoxylin and eosin stained sections of the cryptorchid testis. The size of the epididymal duct was smaller than that of the control testis. Based on Ki67 immunohistochemistry, the proliferative activity of spermatogonia and spermatocytes was significantly decreased in the cryptorchid testis. However, proliferative activity was increased in the epididymal duct. Based on GATA-4 immunohistochemistry, Sertoli cells were relatively resistant to cryptorchidism, and the proliferative activity of Sertoli cells was markedly increased in the cryptorchid testis than in the control testis. These results suggest that spontaneous unilateral cryptorchidism causes morphological defects in spermatogonia and spermatocytes in the testis and changes the size of the efferent ductule of the epididymis. In addition, spontaneous unilateral cryptorchidism increases proliferative activity of Sertoli cells, which may be a predisposing factor for Sertoli cell cancer in cryptorchid testes.
\end{abstract}

Keywords: Dog, efferent ductule, seminiferous tubule, sertoli cells, unilateral cryptorchidism

Received 12 November 2014; Revised version received 9 December 2014; Accepted 11 December 2014

Cryptorchidism is one of the most common congenital defects of the reproductive system in mammals, including dogs and human beings. It is caused by the failure of the scrotum of one or both testes to descent [1]. The incidences of cryptorchidism are $0.8-9.7 \%$ in dogs [2-5] and $1-5 \%$ in human beings [6]. In terms of breed predisposition in dogs, the incidence of cryptorchidism is highest in Chihuahuas, Boxers, and German Shepherds, with incidences of $30.4,20.6$, and $14.0 \%$, respectively [7].

\footnotetext{
${ }^{\#}$ These authors contributed equally to this work.

${ }^{*}$ Corresponding authors: Goo Jang, Department of Anatomy and Cell Biology, College of Veterinary Medicine, Seoul National University, 1 Gwanak-ro, Gwana-gu, Seoul, 151-742, Korea

Tel: +82-2-880-1280; E-mail: snujang@snu.ac.kr

In Koo Hwang, Department of Anatomy and Cell Biology, College of Veterinary Medicine, Seoul National University, 1 Gwanak-ro, Gwana-gu, Seoul, 151-742, Korea

Tel: +82-2-880-1280; E-mail: vetmed2@snu.ac.kr
}

This is an Open Access article distributed under the terms of the Creative Commons Attribution Non-Commercial License (http://creativecommons.org/licenses/ by-nc/3.0) which permits unrestricted non-commercial use, distribution, and reproduction in any medium, provided the original work is properly cited. 
Germ cells, Sertoli cells, and Leydig cells have the potential to proliferate in testicular tissue $[8,9]$. However, the abdominal testis is at increased relative risk of neoplasms such as Sertoli cell tumors and seminomas $[4,10]$. Approximately $70 \%$ of Sertoli cell tumors arising in abdominal testes are functional [10-12]. The prevalence of testicular tumors is higher in dogs than in any other mammalian species $[13,14]$.

GATA-binding proteins (GATA-1 to GATA-6) are structurally related zinc finger proteins and are expressed in blood-forming cells [15-17], heart, gut, yolk sac endoderm, and gonads [18-22]. Among these GATAs, GATA-4 is expressed in mouse Sertoli and Leydig cells throughout fetal and postnatal testicular development $[23,24]$.

There are some reports concerning the incidence of cryptorchidism in dogs [2-5,7] and there are also morphological studies in cryptorchid boars [25,26]. However, there have been no previous reports of the morphology in the cryptorchid and control testis and epididymis of dogs. In this study, we investigated the morphological characteristics and cellular proliferative activity in spermatogenic cells and Sertoli cells in the cryptorchid and control testes and epididymides of a dog.

An 18-month-old German Shepherd with unilateral cryptorchidism was referred to the Seoul National University Veterinary Teaching Hospital, South Korea for elective orchidectomy. The left testis was present within the scrotum but the right testis was not palpable in the scrotum or inguinal area. Laparotomy revealed the cryptorchid testis in the right abdominal region. Both testes were surgically removed.

For histological analysis, both testes were fixed in neutral buffered formalin for 2 days and dehydrated with graded concentrations of alcohol before being embedded in paraffin. Paraffin-embedded tissues were sectioned using a microtome (Leica Microsystems $\mathrm{GmbH}$, Wetzlar, Germany) into 3- $\mu \mathrm{m}$ coronal sections and were mounted onto silane-coated slides (Cat\# 5116-20F, Muto Pure Chemicals Co., Ltd). The sections were stained with hematoxylin and eosin (H\&E) according to the standard protocol.

To ensure that the immunohistochemical data were comparable between control and cryptorchid testis/ epididymis, the sections were carefully processed under the same conditions. The sections were hydrated and treated with $0.3 \%$ hydrogen peroxide $\left(\mathrm{H}_{2} \mathrm{O}_{2}\right)$ in phosphate-buffered saline (PBS) for $30 \mathrm{~min}$. For antigen retrieval, the sections were placed in $400-\mathrm{mL}$ jars filled with citrate buffer ( $\mathrm{pH}$ 6.0) and heated in a microwave oven (Optiquick Compact, Moulinex) operating at a frequency of $2.45 \mathrm{GHz}$ and a $800-\mathrm{W}$ power setting. After three heating cycles of $5 \mathrm{~min}$ each, slides were allowed to cool to room temperature and were washed in PBS. After washing, the sections were incubated in $10 \%$ normal goat serum in PBS for $30 \mathrm{~min}$. They were then incubated with rabbit anti-Ki67 antibody (1:1,000; Abcam, Cambridge, UK), mouse-anti-proliferating cell nuclear antigen (PCNA, 1:1,000) or GATA-4 (1:500, SantaCruz Biotechnology, Santa Cruz, CA) for $48 \mathrm{~h}$ at $4^{\circ} \mathrm{C}$. They were then exposed to biotinylated goat antirabbit IgG, streptavidin peroxidase complex (diluted 1:200, Vector Laboratories, Inc., Burlingame, CA), and visualized with 3,3-diaminobenzidine tetrahydrochloride (Sigma) in 0.1 M Tris-HCl buffer (pH 7.4).

Thirty sections per tissue (control or cryptorchid) were selected from the corresponding areas of each level of testis or epididymis. The number of Ki67-positive or GATA-4 positive cells in each group of sections was counted in the seminiferous tubules using an image analyzing system equipped with a computer-based CCD camera (software: Optimas 6.5, CyberMetrics, Scottsdale, AZ, U.S.A.). Cell counts were obtained by averaging the counts from three seminiferous tubules per section (10 sections).

The data shown here are presented as mean and standard errors of counts performed for each area. The data were evaluated by Student's t-test. Results were considered statistically significant if $P<0.05$.

In the control testis and epididymis, normal spermatogenesis was observed in H\&E-stained sections. Many germ cells and Sertoli cells were observed in the basal seminiferous epithelium of seminiferous tubules. Spermatocytes and spermatids were detected in the vicinity of the lumen in seminiferous tubules (Figure 1A). In the epididymis, cross-sections of the epididymal duct were clearly observed and spermatids were located in the lumen of the duct (Figure 1B). In the cryptorchid testis, few cells were observed in the basal seminiferous epithelium of seminiferous tubules. In addition, spermatocytes and spermatids were rarely observed in the seminiferous tubules (Figure 1C). In the epididymis, the lumen of the epididymal duct was relatively small compared to that in the control epididymis, and interstitial tissue was abundant. In addition, only a few 


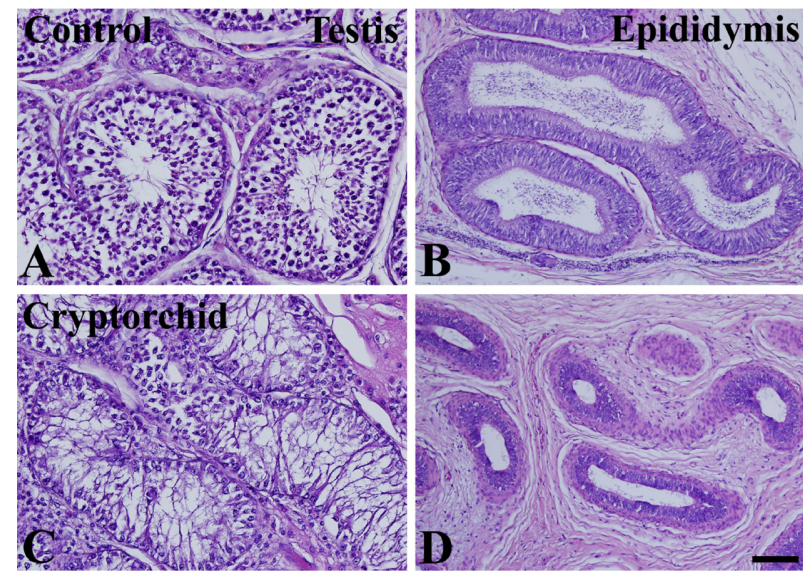

Figure 1. Photomicrographs of hematoxylin and eosin-stained sections of testis ( $A$ and $C$ ) and epididymis (B and $D)$ in unilateral cryptorchidism. In control (intact) testis (A) and epididymis (B), normal spermatogenesis and epididymal duct are present, respectively. In the cryptorchid testis (C), most cells are Sertoli cells, and there are relatively few spermatogonia and spermatocytes. In the cryptorchid epididymis (D), the diameter of the epididymal duct is relatively small. spermatids were observed in the lumen of the epididymal duct (Figure 1D).

In the control testis, abundant Ki67-positive cells were observed in the seminiferous tubules, although there were relatively few Ki67-positive cells in the basal seminiferous epithelium of seminiferous tubules (Figure 2A). Few Ki67-positive cells were observed in the epididymal duct (Figure 2B). In the cryptorchid testis, a few Ki67-positive cells were detected in the basal seminiferous epithelium of seminiferous tubules (Figure 2C), and a few Ki67-positive cells were also observed in the epididymal duct (Figure 2D).

In both control and cryptorchid testis, GATA-4 positive cells were detected in the basal seminiferous epithelium of seminiferous tubules (Figure 3A, 3B). However, the numbers of GATA-4 positive cells were greater in the cryptorchid testis than in the control testis (Figure 3C). In the cryptorchid testis, GATA-4 positive cells were also stained with PCNA (Figure 4A, 4B).

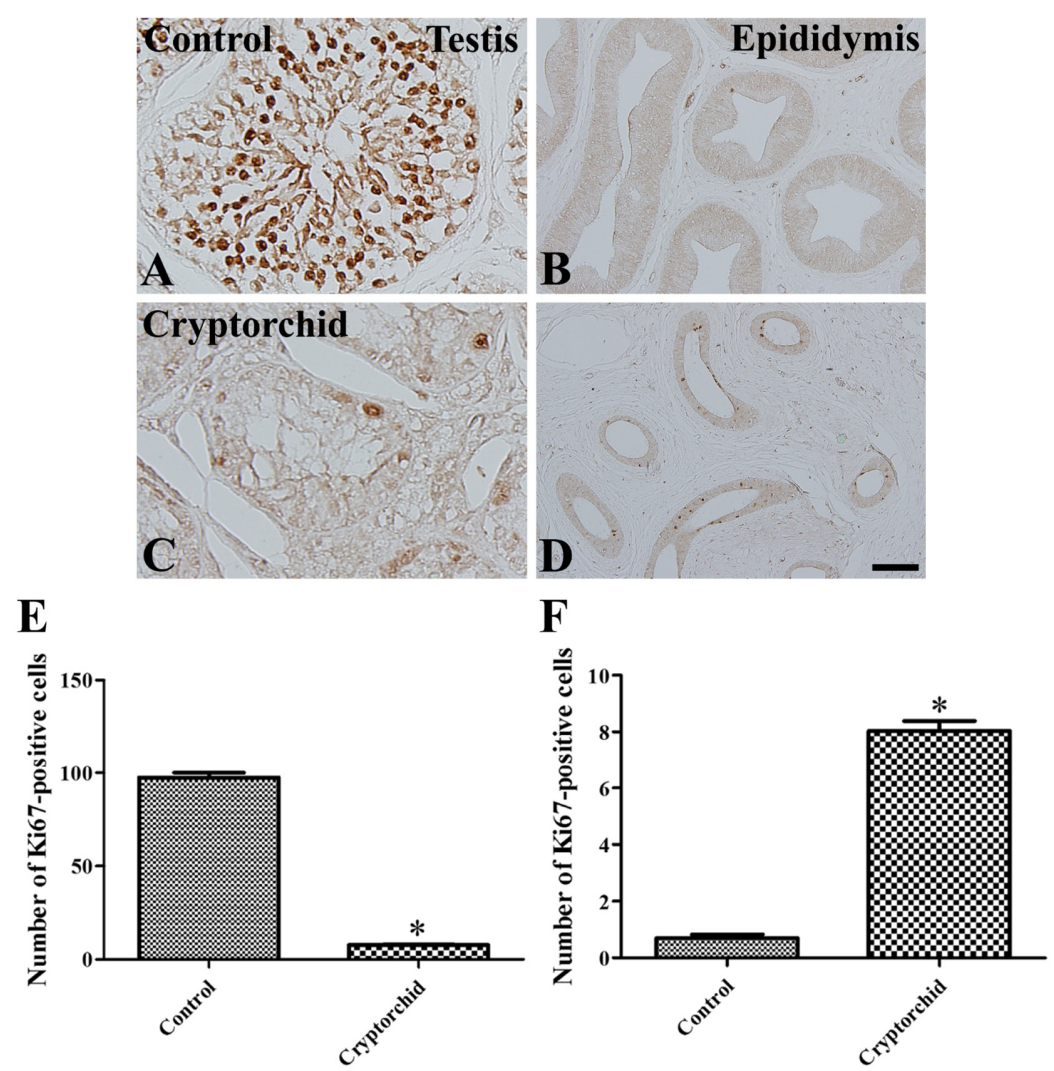

Figure 2. Immunohistochemistry for Ki67 in testis ( $A$ and $C$ ) and epididymis (B and D) in unilateral cryptorchidism. In the control testis (A), a Ki67-positive reaction is detected in most cells, except in the basal seminiferous epithelium of the seminiferous tubules. In the control epididymis (B), Ki67-positive cells are not observed. In the cryptorchid testis (C), Ki67-positive cells are present in the basal seminiferous epithelium of seminiferous tubules. In the cryptorchid epididymis (D), Ki67-positive cells are present in the epididymal duct. $\mathrm{E}$ and $\mathrm{F}$ : The number of Ki67-positive cells per each seminiferous tubule/epididymal duct in testis and epididymis, respectively, in unilateral cryptorchidism (10 sections; ${ }^{*} P<0.05$, control vs. cryptorchid group). All data are shown as the mean $\pm S E$. 

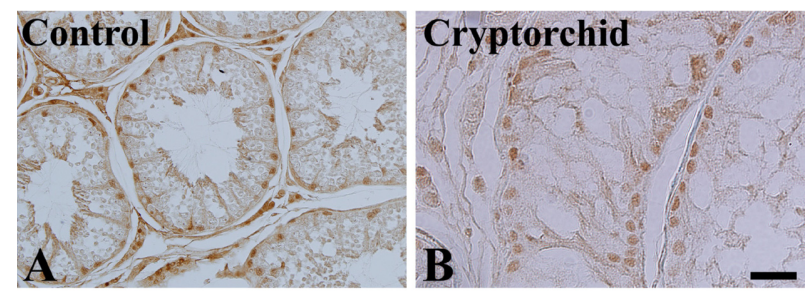

C

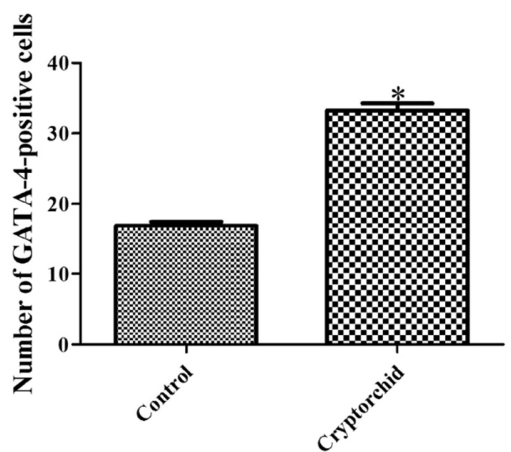

Figure 3. Immunohistochemistry for GATA-4 in testis (A and B) in unilateral cryptorchidism. In the control $(A)$ and cryptorchid (B) testis, GATA-4 positive cells are present in the basal seminiferous epithelium of seminiferous tubules. GATA-4 positive cells are abundant in the cryptorchid testis as compared to the control testis. C: The number of GATA-4 positive cells per seminiferous tubule in testis in unilateral cryptorchidism (10 sections; ${ }^{\star} P<0.05$, control vs. cryptorchid group). All data are shown as the mean \pm SE.

In dogs, cryptorchidism is a common disorder and is mainly of genetic origin [11]. In the present study, we observed the morphology of the control and cryptorchid testes and epididymides in a dog. The unilateral cryptorchidism affected the right testis. The right testis is more frequently affected because it develops in a more cranial position than the left and has a longer distance to travel to reach the scrotum [7,27,28]. There was a significant reduction in the numbers of spermatogonia, spermatocytes, and spermatids in the cryptorchid testis as compared to the control testis. The diameter of the epididymal duct was significantly decreased in the cryptorchid epididymis compared to that in the control epididymis. In addition, the interstitial tissue was relatively abundant in the cryptorchid epididymis. This finding that cryptorchidism changes the histology of the lamina propria, spermatogenic tissue, and interstitial tissue in the testis, resulting in a significant reduction in the number and diameter of seminiferous tubules [26] and a decrease in the number of spermatogonia [29], which results in a reduction in fertility [6] is consistent with that of previous reports.

In the control testis, Ki67-positive cells were abundant in most cells in the seminiferous tubules, but were not

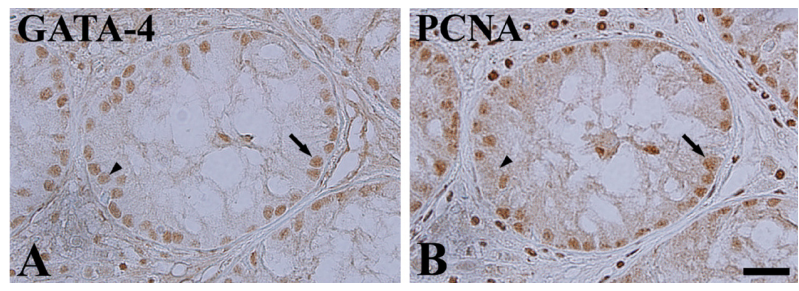

Figure 4. Immunohistochemistry for GATA-4 and PCNA in mirror-imaged testis sections in unilateral cryptorchidism. Most GATA-4 positive cells (arrow) are also labeled with PCNA, but some GATA-positive cells are not co-localized with PCNA (arrowhead)

detected in the epididymal duct. However, in the cryptorchid testis, Ki67-positive cells were only detected in the basal seminiferous epithelium of seminiferous tubules. In addition, Ki67-positive cells were observed in the epididymal duct of the cryptorchid epididymis. This result is consistent with that of a previous study, which found that cell proliferation (as determined by proliferating cell nuclear antigen-positive cells) significantly decreased in experimentally induced cryptorchidism [30]. The proliferative activity of spermatogonia is decreased in cryptorchid testes of male children [31], boars [25] and rabbits [29]. Most proliferating cells in the cryptorchid testis were identified as Sertoli cells based on mirrorimage immunohistochemistry for PCNA and GATA-4. This finding suggests that Sertoli cells in the cryptorchid testis can proliferate and this may increase the risk of Sertoli cell tumors in the cryptorchid testis. This result is consistent with that of previous reports that the prevalence of Sertoli cell tumors in cryptorchid testes of dogs is much higher than that in scrotal testes $[4,10,32]$.

It has been reported that $1-3 \%$ cells are proliferating in the epididymal duct of 2.5-month-old rats, and the cell proliferation decreases with age [33]. In the present study, Ki67-positive cells were rare in the control epididymis, while in the cryptorchid epididymis the number of Ki67-positive cells significantly increased. This result suggests that the epithelium in cryptorchid epididymis can proliferate.

We observed that the cryptorchid testis and epididymis showed defects in morphology, and that cell proliferation was pronounced in the Sertoli cells of the cryptorchid testis and in the epididymal duct. These results indicate that Sertoli cells in the cryptorchid testis have the potential to proliferate, and that this may be associated with the high prevalence of Sertoli cell tumors in cryptorchid testes in dogs. 


\section{Acknowledgments}

This result was supported by BK21 PLUS Program for Creative Veterinary Science Research, Research Institute for Veterinary Science and College of Veterinary Medicine, Seoul National University.

Conflict of interests The authors declare that there is no financial conflict of interests to publish these results.

\section{References}

1. Pinart E, Sancho S, Briz MD, Bonet S, García N. Characterization of the semen quality of postpuberal boars with spontaneous unilateral abdominal cryptorchidism on the right side. Anim Reprod Sci 1999; 55(3-4): 269-278.

2. Kawakami E, Tsutsui T, Yamada Y, Yamauchi M. Cryptorchidism in the dog: occurrence of cryptorchidism and semen quality in the cryptorchid dog. Nihon Juigaku Zasshi 1984; 46(3): 303-308.

3. Priester WA. A summary of diagnoses in the ox, horse, dog and cat from 12 veterinary school clinics in the U. S. and Canada. Vet Rec 1970; 86(22): 654-658.

4. Reif JS, Brodey RS. The relationship between cryptorchidism and canine testicular neoplasia. J Am Vet Med Assoc 1969; 155(12): 2005-2010.

5. Ruble RP, Hird DW. Congenital abnormalities in immature dogs from a pet store: 253 cases (1987-1988). J Am Vet Med Assoc 1993; 202(4): 633-636.

6. Watts LM, Hasthorpe S, Farmer PJ, Hutson JM. Apoptotic cell death and fertility in three unilateral cryptorchid rat models. Urol Res 2000; 28(5): 332-337.

7. Yates D, Hayes G, Heffernan M, Beynon R. Incidence of cryptorchidism in dogs and cats. Vet Rec 2003; 152(16): 502-504.

8. Angelopoulou R, Balla M, Lavranos G, Chalikias M, Kitsos C, Baka S, Kittas C. Sertoli cell proliferation in the fetal and neonatal rat testis: a continuous phenomenon? Acta Histochem 2008; 110(4): 341-347.

9. Sriraman V, Rao VS, Sairam MR, Rao AJ. Effect of deprival of LH on Leydig cell proliferation: involvement of PCNA, cyclin D3 and IGF-1. Mol Cell Endocrinol 2000; 162(1-2): 113-120.

10. Hayes HM Jr, Wilson GP, Pendergrass TW, Cox VS. Canine cryptorchism and subsequent testicular neoplasia: case-control study with epidemiologic update. Teratology 1985; 32(1): 51-56.

11. Feldman EC, Nelson RW. Canine and feline endocrinology and reproduction, 2nd ed, Saunders, Philadelphia, 1987; pp 481-523.

12. Quartuccio M, Marino G, Garufi G, Cristarella S, Zanghì A Sertoli cell tumors associated with feminizing syndrome and spermatic cord torsion in two cryptorchid dogs. J Vet Sci 2012; 13(2): 207-209.

13. Cohen D, Reif JS, Brodey RS, Keiser H. Epidemiological analysis of the most prevalent sites and types of canine neoplasia observed in a veterinary hospital. Cancer Res 1974; 34(11): 2859-2868.

14. Dow C. Testicular tumours in the dog. J Comp Pathol 1962; 72 247-265.

15. Pandolfi PP, Roth ME, Karis A, Leonard MW, Dzierzak E, Grosveld FG, Engel JD, Lindenbaum MH. Targeted disruption of the GATA3 gene causes severe abnormalities in the nervous system and in fetal liver haematopoiesis. Nat Genet 1995; 11(1): 40-44.

16. Pevny L, Simon MC, Robertson E, Klein WH, Tsai SF, D'Agati V, Orkin SH, Costantini F. Erythroid differentiation in chimaeric mice blocked by a targeted mutation in the gene for transcription factor GATA-1. Nature 1991; 349(6306): 257-260.
17. Tsai FY, Keller G, Kuo FC, Weiss M, Chen J, Rosenblatt M, Alt $\mathrm{FW}$, Orkin SH. An early haematopoietic defect in mice lacking the transcription factor GATA-2. Nature 1994; 371(6494): 221-226.

18. Arceci RJ, King AA, Simon MC, Orkin SH, Wilson DB. Mouse GATA-4: a retinoic acid-inducible GATA-binding transcription factor expressed in endodermally derived tissues and heart. Mol Cell Biol 1993; 13(4): 2235-2246.

19. Morrisey EE, Ip HS, Lu MM, Parmacek MS. GATA-6: a zinc finger transcription factor that is expressed in multiple cell lineages derived from lateral mesoderm. Dev Biol 1996; 177(1): 309-322.

20. Morrisey EE, Ip HS, Tang Z, Lu MM, Parmacek MS GATA-5: a transcriptional activator expressed in a novel temporally and spatially-restricted pattern during embryonic development. Dev Biol 1997; 183(1): 21-36.

21. Narita N, Heikinheimo M, Bielinska M, White RA, Wilson DB. The gene for transcription factor GATA-6 resides on mouse chromosome 18 and is expressed in myocardium and vascular smooth muscle. Genomics 1996; 36(2): 345-348.

22. Soudais C, Bielinska M, Heikinheimo M, MacArthur CA, Narita N, Saffitz JE, Simon MC, Leiden JM, Wilson DB. Targeted mutagenesis of the transcription factor GATA-4 gene in mouse embryonic stem cells disrupts visceral endoderm differentiation in vitro. Development 1995; 121(11): 3877-3888.

23. Ketola I, Rahman N, Toppari J, Bielinska M, Porter-Tinge SB, Tapanainen JS, Huhtaniemi IT, Wilson DB, Heikinheimo M. Expression and regulation of transcription factors GATA-4 and GATA-6 in developing mouse testis. Endocrinology 1999; 140(3): 1470-1480.

24. Viger RS, Mertineit C, Trasler JM, Nemer M. Transcription factor GATA-4 is expressed in a sexually dimorphic pattern during mouse gonadal development and is a potent activator of the Müllerian inhibiting substance promoter. Development 1998; 125(14): 2665-2675.

25. Bernal-Mañas CM, Morales E, Pastor LM, Pinart E, Bonet S, Rosa Pde L, Dolors Briz M, Zuasti A, Ferrer C, Canteras M. Proliferation and apoptosis of spermatogonia in postpuberal boar (Sus domesticus) testes with spontaneous unilateral and bilateral abdominal cryptorchidism. Acta Histochem 2005; 107(5): 365372.

26. Pinart E, Sancho S, Briz M, Bonet S. Morphologic study of the testes from spontaneous unilateral and bilateral abdominal cryptorchid boars. J Morphol 1999; 239(3): 225-243.

27. Brearley MJ. The urogenital system. In: Manual of small animal oncology (White RAS, ed), British small animal veterinary association, Gloucester, 1991; pp 306-307.

28. Nielsen SW, Kennedy PC. Tumors of the genital system. In: Tumors in domestic animals (Moulton JE, ed), 3rd ed, University of California Press, Berkeley, 1990; pp 479-513.

29. Zhang RD, Wen XH, Kong LS, Deng XZ, Peng B, Huang AP, Wan Y, Yang ZW. A quantitative (stereological) study of the effects of experimental unilateral cryptorchidism and subsequent orchiopexy on spermatogenesis in adult rabbit testis. Reproduction 2002; 124(1): 95-105.

30. Kazusa K, Namiki Y, Asano A, Kon Y, Endoh D, Agui T. Differences in spermatogenesis in cryptorchid testes among various strains of mice. Comp Med 2004; 54(2): 179-184.

31. Markewitz M, Lattimer JK, Veenema RJ. A comparative study of germ cell kinetics in the testes of children with unilateral cryptorchidism: a preliminary report. Fertil Steril 1970; 21(11): 806-815.

32. Hong S, Lee HA, Han SJ, Kim O. Spontaneous sertoli cell tumor with cryptorchism in a beagle dog. Lab Anim Res 2011; 27(2): 177-178.

33. Clermont Y, Flannery J. Mitotic activity in the epithelium of the epididymis in young and old adult rats. Biol Reprod 1970; 3(3): 283-292. 